\title{
$\lg A$ and IgG antibodies to distinct serotypes of Mycobacterium avium in HIV seropositivity and AIDS
}

\author{
HAYDEE E. HERNANDEZ-MUNOZ and J. L. STANFORD \\ Department of Bacteriology, University College London Medical School, 67-73 Riding House Street, London \\ WIP 7LD
}

\begin{abstract}
IgA and IgG antibodies to cytoplasmic and secreted antigens of serotypes 4 and 8 of Mycobacterium avium and the percentage of agalactosyl immunoglobulin (\%Gal[0]) were measured by ELISA in groups of blood donors, HIV seronegative persons, HIV seropositive persons with $\mathrm{CD4}^{+}$cell counts $>300 / \mathrm{mm}^{3}$ and AIDS patients co-infected with $M$. avium. No differences were found between the control groups, but HIV seropositive persons were distinguished by their increased \%Gal[0] $(p<0.001)$ and increased IgA titre $(p<0.05)$ to secreted antigens of both serotypes of $M$. avium. Patients going on to develop aviumosis differed from other HIV-positive individuals, having more IgA to secreted antigens of serotype $8(p<0.03)$ and more IgG to secreted antigens of both serotypes $(p<0.001)$. After developing $M$. avium infection there was a further increase in \%Gal[0] $(p<0.0001)$, IgA titres fell to both types of antigen from serotype $4(p<0.01)$ and sonicate antigen of serotype $8(p<0.001)$ and IgG fell to the secreted antigens of serotype $4(p<0.03)$. One interpretation of these observations is that antibody profiles to $M$. avium might be used to identify healthy persons at special risk of developing HIV seropositivity, and to identify persons with early AIDS who are likely to develop aviumosis.
\end{abstract}

\section{Introduction}

Since the report of the first case of acquired immunodeficiency syndrome (AIDS) in 1981, Mycobacterium avium has been found to be responsible for opportunist disseminated infection (aviumosis) in up to $50 \%$ of patients in some countries [1]. Data from the UK suggest that c. $20 \%$ of HIV seropositive patients develop aviumosis as part of AIDS, although this might be reduced by the use of prophylactic antibiotics [2]. Most patients, once infected with $M$. avium, remain so until their death which often follows within 9 months [1]. At first, many cases were diagnosed only at autopsy, but improved bacteriological techniques have led to earlier detection of the infection. It was thought that such infections were also due to $M$. intracellulare, but now it is realised that this and other mycobacterial species are associated with only occasional cases of infection in HIV seropositive persons [3].

The source of infection with $M$. avium is presumed to be environmental $[4,5]$, but the timing of infection is less certain. There is evidence that it can be shortly before disease in some patients [6], and earlier in

Received 23 March 1995; accepted 29 June 1995. others, suggesting activation of endogenous infection. Disease is commonly associated with particular agglutination serotypes of the species, varying from country to country $[3,7]$. Amongst the most frequently incriminated serotypes in the UK and the USA, are 4, 8 and 1 , in that order. The first two of these belong to the subspecies $M$. avium brunense, and the third to the type subspecies [8]. Serotype restriction is probably not by chance, but depends on their differential virulence, the frequency with which they are encountered and the immunological experience of the patient.

Studies [9] have shown that skin testing can differentiate between Aviumins (new tuberculins) prepared from serotypes 4 and 8 , and that the distribution of positivity in healthy subjects is similar to that of the aviumosis occurring in AIDS patients of the same age range. The question awaits answer as to whether a person skin test positive to a relevant serotype whilst healthy, will develop aviumosis due to this serotype on developing AIDS. The present study examined whether the use of serological techniques might enable detection of HIV seropositive patients at especial risk of developing $M$. avium infection, and perhaps identify healthy persons at special risk of becoming HIV seropositive. 


\section{Materials and methods}

\section{Study population and sera}

These were mainly patients attending the sexually transmitted diseases clinics at University College Hospital or at King's College Hospital in London. They included 24 homosexual patients found to be HIV seronegative by the Wellcozyme HIV $1+2$ test (mean age 33.7 years) and 56 HIV seropositive patients. Of these, 37 were asymptomatic men with $\mathrm{CD4}^{+}$counts $>300 / \mathrm{mm}^{3}$ (mean age 33.4 years), and $19 \mathrm{had}$ an AIDS diagnosis and were suffering from aviumosis (17 men and two women, mean age 39.2 years). Sera were obtained from each person, and from the 19 with aviumosis stored samples were available from before the superinfection was diagnosed. A further 24 sera were obtained from blood donors, representing healthy controls.

\section{Preparation of antigens}

The strains of $M$. avium selected were one of serotype 4 and one of serotype 8 isolated from AIDS patients and identified and supplied by Dr P. A. Jenkins, PHLS Mycobacterium Reference Unit, Cardiff. They were cultured on Sauton's medium solidified with agar 1.2\% and incubated at $35^{\circ} \mathrm{C}$ until plentiful growth was obtained (usually 6-8 weeks). Bacilli harvested from the medium were sonicated in $\mathrm{M} / 15$ borate-buffered saline, $\mathrm{pH} 8.0$, to produce a cytoplasmic and a cell wall preparation. Spent medium was broken into small pieces in an equal volume of the same buffer and incubated at $4^{\circ} \mathrm{C}$ for $24 \mathrm{~h}$, to produce a crude extract of secreted antigens. Both types of preparation were membrane-filtered $(0.2 \mu \mathrm{m})$ and their protein contents were estimated by a spectrophotometric method [10]. The reagents were standardised to a protein concentration of $1 \mathrm{mg} / \mathrm{ml}$ and stored in small volumes at $4^{\circ} \mathrm{C}$ until required.

\section{ELISA tests}

A modified indirect ELISA method was used to detect antibodies binding to each antigen preparation. Microtitration plates were coated with the individual antigen reagents at $5 \mu \mathrm{g} / \mathrm{ml}$ of carbonate-bicarbonate buffer, pH 9.6, prepared in sterile non-pyrogenic water (Baxter Healthcare Ltd). The following day, after washing and blocking with phosphate buffer containing Tween 20 and bovine serum albumin $1 \%$ in non-pyrogenic water, $100-\mu l$ volumes of sera diluted 1 in 250 for IgA or 1 in 1000 for IgG were added to each well. After incubation at $37^{\circ} \mathrm{C}$ for $2 \mathrm{~h}$, and washing, peroxidase-conjugated rabbit antisera to human IgA alpha chains and IgG gamma chains (Dakopatts, Denmark) diluted 1 in 1000 and 1 in 2000 , respectively, were added $(100 \mu \mathrm{l} /$ well $)$. Plates were incubated at $4^{\circ} \mathrm{C}$ overnight, washed and $100 \mu$ l of substrate (2-2 Azino-di-3-ethyl benzthiazoline sulphonic acid; Sigma, A-1888 ABTS) dissolved in $0.05 \mathrm{M}$ citrate phosphate buffer, $\mathrm{pH} 4.1$, were added to each well. After incubation in the dark for $30 \mathrm{~min}$, the enzymic reaction was stopped by adding $100 \mu \mathrm{l}$ of sodium flouride $1 \%$ solution and the developed colour was measured in a Dynatech MR 5000 ELISA reader at $490 \mathrm{~nm}$ and $630 \mathrm{~nm}$.

\section{Agalactosyl immunoglobulin $G$}

The percentage of agalactosyl immunoglobulin (\%Gal[0]) was determined by the methods described by van Zeben et al. [11]. Microtitration plates were coated with protein $\mathrm{A}$ and remaining protein binding sites were blocked with Tween 20 and bovine serum albumin. Sera diluted 1 in 100 in glycine buffer were added and plates were incubated at $37^{\circ} \mathrm{C}$ for $2 \mathrm{~h}$. Plates were washed and placed in a water bath at $80^{\circ} \mathrm{C}$ for $7-$ $8 \mathrm{~min}$ to denature the bound antibody and expose the relevant sugar chains. The cooled plates were dried, biotinylated monoclonal antibody to $\mathrm{N}$-acetylglucosamine was added and plates were incubated overnight. After washing again, streptavidin (Dakopatts) was added to each well and plates were incubated for $1 \mathrm{~h}$ at $37^{\circ} \mathrm{C}$. Colour reagent (2-2 Azino-di-3-ethyl benzthiazoline sulphonic acid) was added to washed plates and colour was allowed to develop for $15 \mathrm{~min}$, then the reaction was stopped and optical densities were read at $490 \mathrm{~nm}$ and $630 \mathrm{~nm}$.

A curve fitting programme (Dataplot by S. M. Fraser, Strathclyde University, Glasgow) was utilised to plot the optical densities of standards and results were calculated by log-linear interpolation of test optical densities against the standard optical density corrected for inter-plate variation. The final $\% \mathrm{Gal}[0]$ obtained was corrected for age from previously published values for specific ages [12].

\section{Statistical treatment of results}

Student's $t$ test and, where applicable, the paired $t$ test, were applied to all the results presented.

\section{Results}

\section{Antibodies to mycobacteria}

Results for IgA are shown in Figs $1 \mathrm{a}$ and $\mathrm{b}$, and for IgG in Figs $2 a$ and $b$. Sera from healthy blood donors and HIV seronegative persons responded similarly to both serotypes. They contained more $\operatorname{IgA}$ to sonicate than secreted antigens $(p<0.05)$ and more IgG to secreted than sonicate antigens $(p<0.05)$.

The asymptomatic HIV seropositive group with $\mathrm{CD} 4^{-}$ T cell counts $>300 / \mathrm{mm}^{3}$ had significantly higher IgA titres to secreted antigens of both serotypes than had the healthy controls $(p<0.05)$. Whereas they did not show the significant increase in IgA to sonicated over secreted antigens of serotype 4 seen in the controls, 

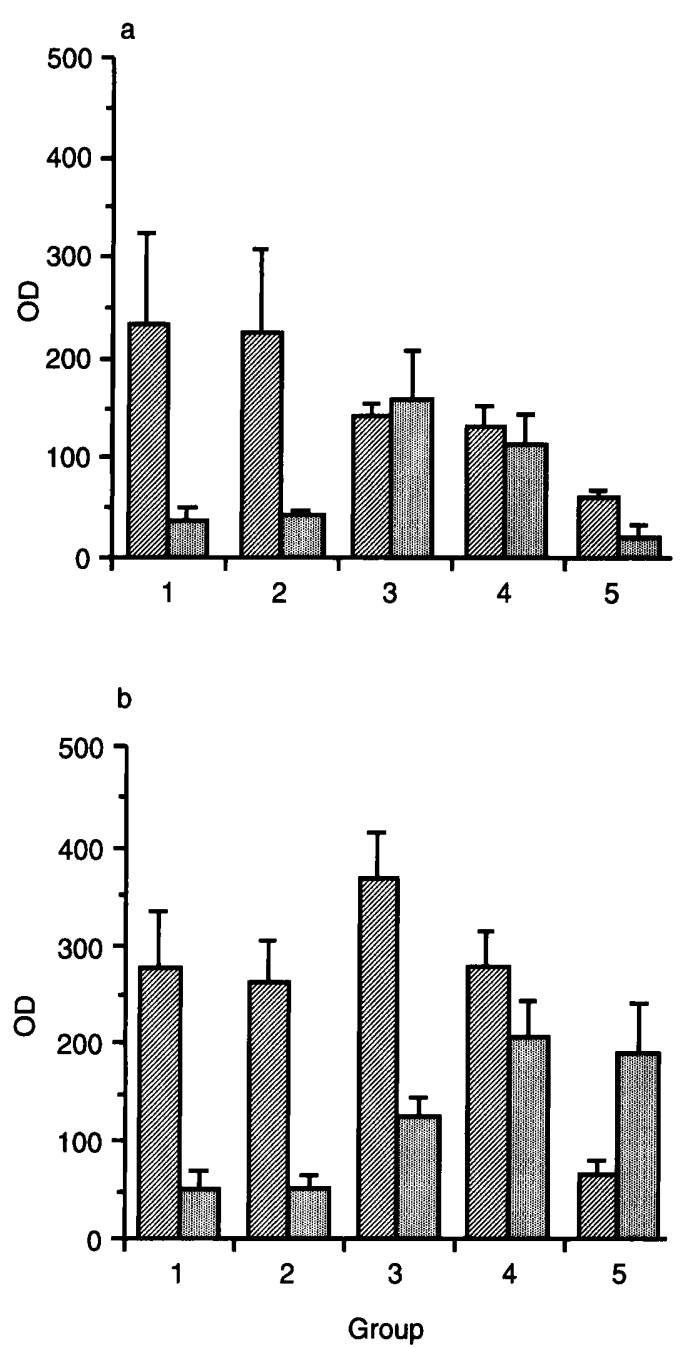

Fig. 1. Histograms showing the optical density readings of IgA antibodies to sonicate $\square$ and secreted antigens of $M$. avium, a, serotype 4 ; b, serotype 8 . The groups of people tested were: (1) healthy blood donors; (2) HIV seronegative attenders at sexually transmitted diseases clinics; (3) HIV seropositive patients with $\mathrm{CD}^{+}$counts above $300 / \mathrm{mm}^{3}$; (4) AIDS patients prior to diagnosis of $M$. avium infection; (5) the same AIDS patients after diagnosis of $M$. avium infection.

their titres were higher to sonicate than to secreted antigens of serotype $8(p<0.001)$, and to the sonicate of serotype 8 than to that of serotype $4(p<0.001)$. They had similar IgG titres to all four antigens, which did not differ significantly from those of healthy individuals.

HIV seropositive persons prior to developing aviumosis differed from other HIV serpositive persons in their higher IgA titres to secreted antigens of serotype $8(p<0.03)$ and higher IgG titres to secreted antigens of both serotypes $(p<0.001)$ and to sonicate antigen of serotype $8(\mathrm{p}<0.02)$. After developing aviumosis, further significant changes could be shown by paired $t$ tests. Notably there was a fall in IgA titres to both sonicates $(p<0.001)$ and to the secreted antigens of a

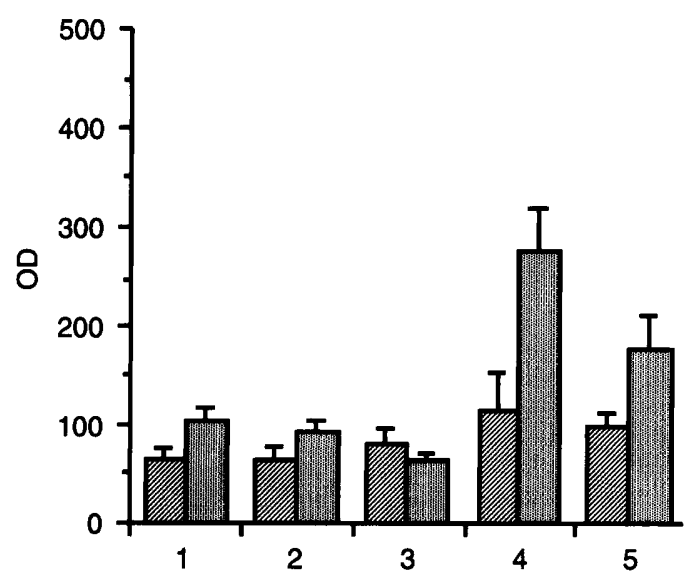

b

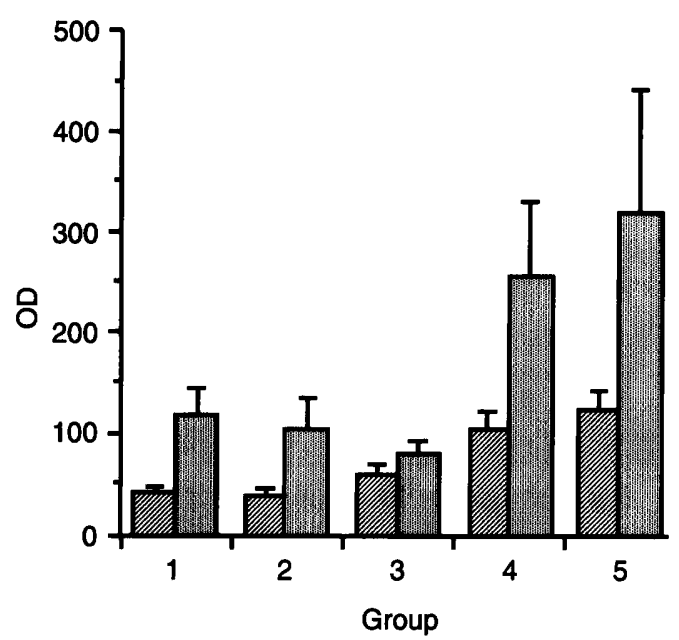

Fig. 2. Histograms showing the optical density readings of IgG antibodies to sonicate $\square$ and secreted $⿴ 囗 十)$ antigens of $M$. avium, a, serotype $4 ; \mathbf{b}$, serotype 8 . The groups of people tested were: (1) healthy blood donors; (2) HIV seronegative attenders at sexually transmitted diseases clinics; (3) HIV seropositive patients with $\mathrm{CD}^{+}$counts above $300 / \mathrm{mm}^{3}$; (4) AIDS patients prior to diagnosis of $M$. avium infection; (5) The same AIDS patients after diagnosis of $M$. avium infection.

serotypes $4(p=0.01)$, and a fall in IgG titre to the secreted antigens of serotype $4(p<0.03)$.

\section{Agalactosyl immunoglobulin}

The mean excess $\% \mathrm{Gal}[0]$, after correction for age, is shown in Table 1. HIV seropositive persons had significantly higher values than HIV seronegative persons $(p<0.0007)$, with a further significant rise on development of aviumosis $(p<0.004)$. Pre-aviumosis sera of the patients subsequently developing this infection did not differ from the other HIV positive group, but with the development of $M$. avium infection almost every patient showed a further increase; the increases were significant by the paired $t$ test $(\mathrm{p}<0.0001)$. 
Table 1. The mean percentages and standard deviations of agalactosyl IgG $(\% \mathrm{Gal}[0])$ in the study groups in excess of the age corrected normal values

\begin{tabular}{lcccc}
\hline $\begin{array}{l}\text { Subject } \\
\text { group }\end{array}$ & $\begin{array}{c}\text { Number } \\
\text { of patients }\end{array}$ & $\begin{array}{c}\text { Mean } \\
\% \mathrm{Gal}[0]\end{array}$ & (SD) & Probability (2-tail) \\
\hline HIV negative & 24 & 5.1 & $(6.9)$ & $\mathrm{p}=0.0007$ \\
HIV positive & 56 & 11.7 & $(7.8)$ & $\mathrm{p}<0.004$ \\
HIV positive post- $M$. avium & 19 & 18.3 & $(9.1)$ & $\mathrm{p}<0.0001$ (paired $t$ test) \\
HIV positive pre- $M$. avium & 19 & 10.0 & $(11.5)$ & \\
\hline
\end{tabular}

\section{Discussion}

The results pose some questions that may be fundamental to HIV-associated disease. Why should asymptomatic HIV seropositive patients differ from blood donors and other HIV seronegative persons in their IgA titres to mycobacteria $(p<0.05)$ ? Taken with their raised \%Gal[0] $(\mathrm{p}<0.0007)$ and their inability to respond in skin tests to group i common mycobacterial antigens [9], the results suggest that HIV seropositivity develops in a particular subgroup. One explanation might be that their T-cell activity is predominantly of type 2 as proposed by Clerici and Shearer [13] and further evidence for this might be obtained from an analysis of the subclasses of IgG to M. avium.

Another question concerns HIV seropositive persons who subsequently develop aviumosis; why should their sera differ from those of other HIV positive people? It might indicate that infection with $M$. avium is already present but if this were so, the $\% \mathrm{Gal}[0]$ might have been raised further, which it was not. Nonetheless, an increase in IgG to the secreted antigens $(p<0.001)$ does suggest either prior contact with these serotypes, or that bacilli were present and actively secreting at the time the samples were taken.

M. avium serotype 4 , which is frequently associated with aviumosis in AIDS patients in the UK, and serotype 8 , which less frequently causes the disease, were specifically selected for this study; because of their similarity the differences in antibody titres to them is surprising. These differences coincide with those found in skin test responsiveness by Khoo et al. [9]. With the development of aviumosis, reductions in titres suggest that circulating IgA and IgG to serotype 4-specific determinants on secreted antigens may be removed due to complex formation. It was interesting that antibodies to secreted antigens, rather than sonicates, showed the distinction between serotypes. Sonicate preparations largely consist of antigens released when bacilli die, and the fall in $\operatorname{IgA}$ titres to them may reflect their release by the bactericidal action of antibiotics the patients were receiving, and subsequent complex formation. Alternatively, the findings may reflect a failing ability to produce antibodies to a continuing challenge with a particular serotype, or the fall in titre may precede the establishment of infection.
The \%Gal[0] is increased in chronic diseases in which T-cell mediated cell death is taking place and in HIV seropositive persons may be a marker of $\mathrm{T}$ cells mediating the death of other $\mathrm{T}$ cells. The further rise with developing $M$. avium disease $(\mathrm{p}<0.0001)$ shows that regulatory mechanisms are still operative late in AIDS. This additional rise in \%Gal[0] does not occur in AIDS without mycobacteral co-infection (unpublished observations). Although it would be difficult to prove that loss of galactose is directly associated with the antibodies to mycobacteria measured, paired $t$ tests suggest a relationship between $\% \mathrm{Gal}[0]$ and IgG titres to secreted antigens of serotype 8 , before $(p<0.005)$ and after $(\mathrm{p}<0.03) M$. avium infection.

In conclusion, the importance of this work is not merely descriptive, as it may indicate ways of detecting those at risk of developing HIV seropositivity. Such individuals most require vaccination against HIV, which may not need to be specific to the virus, but aimed at correcting a predisposition. Thus does BCG, under favourable circumstances, prime an individual to respond to a mycobacterial challenge in a way that is protective, rather than by enhancing responses to species-specific antigens of the tubercle bacillus. The results of this study also suggest that HIV seropositive individuals likely to develop aviumosis might be recognised. This would allow some selection of those particularly requiring chemoprophylaxis against $M$. avium disease which is both expensive and potentially toxic.

We thank Drs A. Pozniak of the Department of Genitourinary Medicine, King's College Hospital, R. Miller of the Department of Medicine and R. Gilson of the Department of Genitourinary Medicine of University College London Medical School, for the provision of sera.

\section{References}

1. Horsburgh CR, Selik RM. The epidemiology of disseminated nontuberculous mycobacterial infection in the Acquired Immunodeficiency Syndrome (AIDS). Am Rev Respir Dis 1989; 139: 4-7.

2. Nightingale SD, Cameron DW, Gordin FM et al. Two controlled trials of rifabutin prophylaxis against Mycobacterium avium complex infection in AIDS. N Engl J Med 1993; 329: $828-833$.

3. Yakrus MA, Good RC. Geographic distribution, frequency and specimen source of Mycobacterium avium complex serotypes isolated from patients with acquired immunodeficiency syndrome. J Clin Microbiol 1990; 28: 926-929. 
4. Grange JM, Yates MD, Boughton E. The avian tubercle bacillus and its relatives. J Appl Bacteriol 1990; 68: 411-431

5. Horsburgh CR, Chin DP, Yajko DM et al. Environmental risk factors for acquisition of Mycobacterium avium complex in persons with human immunodeficiency virus infection. $J$ Infect Dis 1994; 170: 362-367.

6. von Reyn CF, Maslow JN, Barber TW, Falkinham JO, Arbeit $\mathrm{RD}$. Persistent colonisation of potable water as a source of Mycobacterium avium infection in AIDS. Lancet 1994; 343: 1137-1141.

7. Hoffner SE, Kallenius G, Petrini B, Brennan PJ, Tsang AY. Serovars of Mycobacterium avium complex isolated from patients in Sweden. J Clin Microbiol 1990; 28: 1105-1107.

8. McIntyre G, Stanford JL. The relationship between immunodiffusion and agglutination serotypes of Mycobacterium avium and Mycobacterium intracellulare. Eur J Respir Dis 1986; 69: 135-141.
9. Khoo SH, Wilkins EGL, Fraser I, Stanford JL. Lack of T cell response to common mycobacterial antigens in HIV-infected individuals - consequence or a co-factor? IX International Conference on AIDS, Berlin, June 1993. Abstract no. PO-A240551.

10. Warburg BL, Christian T. A method of protein estimation. Biochemische Zeitschrift 1941; 310: 384-386.

11. van Zeben D, Rook GAW, Hazes JMW et al. Early agalactosylation of IgG is associated with a more progressive disease course in patients with rheumatoid arthritis: results of a follow-up study. $B r J$ Rheumatol 1994; 33: 36-43.

12. Parekh R, Roitt I, Isenberg D, Dwek R, Rademacher T. Agerelated galactosylation of the $\mathrm{N}$-linked oligosaccharides of human serum IgG. $J$ Exp Med 1988; 167: 1731-1736.

13. Clerici M, Shearer GM. A TH1 to TH2 switch is a critical step in the etiology of HIV infection. Immunol Today 1993; 14: $107-110$. 